\title{
Article \\ Expectations of Future Natural Hazards in Human Adaptation to Concurrent Extreme Events in the Colorado River Basin
}

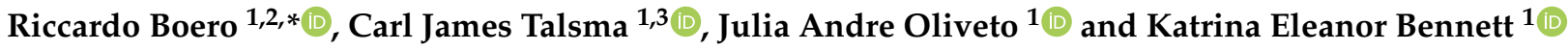 \\ 1 Los Alamos National Laboratory, P.O. Box 1663, Los Alamos, NM 87545, USA; \\ carl.talsma@carbonsolutionsllc.com (C.J.T.); joliveto@lanl.gov (J.A.O.); kbennett@lanl.gov (K.E.B.) \\ 2 Norwegian Institute for Air Research-NILU, P.O. Box 100, 2027 Kjeller, Norway \\ 3 Carbon Solutions LLC, 520 S Walnut St. \#937, Bloomington, IN 47402, USA \\ * Correspondence: ribo@nilu.no; Tel.: +47-63898217
}

\section{check for}

updates

Citation: Boero, R.; Talsma, C.J.;

Oliveto, J.A.; Bennett K.E. Future

Hazards and Adaptation to Extreme

Events. Climate 2022, 10, 27. https://

doi.org/10.3390/cli10020027

Academic Editor: Alban Kuriqi

Received: 11 January 2022

Accepted: 11 February 2022

Published: 18 February 2022

Publisher's Note: MDPI stays neutral with regard to jurisdictional claims in published maps and institutional affiliations.

Copyright: (C) 2022 by the authors. Licensee MDPI, Basel, Switzerland. This article is an open access article distributed under the terms and conditions of the Creative Commons Attribution (CC BY) license (https:// creativecommons.org/licenses/by/ $4.0 /)$

\begin{abstract}
Human adaptation to climate change is the outcome of long-term decisions continuously made and revised by local communities. Adaptation choices can be represented by economic investment models in which the often large upfront cost of adaptation is offset by the future benefits of avoiding losses due to future natural hazards. In this context, we investigate the role that expectations of future natural hazards have on adaptation in the Colorado River basin of the USA. We apply an innovative approach that quantifies the impacts of changes in concurrent climate extremes, with a focus on flooding events. By including the expectation of future natural hazards in adaptation models, we examine how public policies can focus on this component to support local community adaptation efforts. Findings indicate that considering the concurrent distribution of several variables makes quantification and prediction of extremes easier, more realistic, and consequently improves our capability to model human systems adaptation. Hazard expectation is a leading force in adaptation. Even without assuming increases in exposure, the Colorado River basin is expected to face harsh increases in damage from flooding events unless local communities are able to incorporate climate change and expected increases in extremes in their adaptation planning and decision making.
\end{abstract}

Keywords: climate and weather extremes; copulas; flooding; investment model; climate change

\section{Introduction}

Human adaptation is the capability of human systems to adjust in response to climatic stimuli and their impacts [1]. It is a complex social mechanism that requires local communities [2-5] to continuously assess current and future hazards and the resources at stake, and consequently to implement multi-year strategies to mitigate expected risks. Improved adaptation by humans to extreme events can result in decreased social consequences and reduced economic risk to impacts of the extremes. This means that society can develop higher resiliency in the face of such extreme events [6].

Currently, state-of-the-art science considers climate and weather extremes but defines them independently and, thus, a critical gap exists in understanding their consequences of these extremes on human, social, and economic systems. Extreme events are, in fact, highly coupled feedback to the regional and global climate and exacerbate threshold behavior, where thresholds are tipping points resulting in new climate and ecological equilibria $[7,8]$. Recent events in the US and globally highlight that these cumulative events have the potential to exhibit threshold behaviour [9-13]; thus, we require approaches to define and consider extremes events in this coupled mode [14,15]. In fact, as noted in ([16] p. 21) a major challenge to the modeling of the human systems impacts of extreme events is the assessment of specific characteristics of each hazard. Consequently, improved assessment of hazard strongly impacts the quantification and attribution of its associated damages [17] and enables accurate and fine-scale investigations of adaptation processes. 
As communities face climate stimuli and impacts, they must decide how to manage such risks by identifying which strategies can be used to mitigate risks. Since such strategies are always expensive, communities need to carefully select the ones that are adopted and implemented. Communities' adaptation decisions are, thus, also considered investment decisions, where the upfront cost of an adaptation strategy (e.g., a building code, the building of a reservoir, and the grounding of power lines) must be offset by the benefit of avoiding future economic and social losses. Scientific analyses of these adaptation decisions, therefore, usually focus on three main variables: climate and weather stimuli are the natural "hazards" considered (1); human activities and assets are what are "exposed" to the hazard and that could be entirely or partially "damaged" and lost (2); and adaptation is conceived and measured by its complement value, damage (3). Adaptation analysis is dependent on our capability to precisely quantify the other two main variables involved: hazard and exposure.

Modeling adaptation as an investment decision is consistent with the most recent conceptual approaches for investigating and managing climate risks (e.g., [18]) and has been used effectively to shed light on human adaptation to large- [19,20] and small- [21] scale extreme events. Following [21,22], adaptation decisions are inherently forward-looking because investments benefits will materialize in the future. For instance, new building codes and situating houses at higher elevations can protect properties situated in flood-prone areas, dams and reservoirs can protect against floods and droughts, and prescribed fires and mechanical treatments of hazardous fuels can be effective against wildfires. Recent empirical analyses of strategies for adapting to flood risks at the individual [23] and community levels $[24,25]$ confirm the pivotal role of experienced events and climate change predictions on expected risks and mitigation. Thus, there is a need to precisely model the role that expectations about future natural hazards have on adaptation levels, with the aim of quantifying the value of expectations as good policy levers for supporting local communities in managing climatic risks.

In the U.S., critical watersheds play a fundamental role in regulating water resources for the economy and society ([26]. One of the most important U.S. watersheds is the Colorado River basin, which provides water for over 40 million people and contributes 1.4T to the U.S. economy (estimated in 2014 U.S. dollars, [27]). In the Southwest climate region (Arizona, New Mexico, Colorado, and Utah), flooding, drought, freezing events, severe storms, and winter storms events cost approximately 36 billion dollars and resulted in 770 deaths between 1980 and 2020 ([28]). The importance of the Colorado and the potential impact of changing extremes on the economy of the basin highlights the need for closer examination of changing concurrent extreme events ([29-31]).

In this paper, we introduce two main methodological novelties to consider the expectation of natural hazard. We introduce an approach to representing concurrent extreme events applied to flooding that makes the quantification and prediction of natural hazards and of their cumulative impacts easier and more realistic. Then, we transform and apply data sets at a very fine spatial and temporal scale for the calibration of our adaptation model [32], using the U.S. portion of the Colorado River Basin (CRB) as a case study for this work. The adaptation model evaluates the damage induced by natural hazards at a quarterly time scale and at Census block spatial level. We focus on flooding hazards as one of the natural disturbances most negatively impacting human systems [33]. Although the focus is on flooding and on a specific U.S. river basin, our approach could be applied to any kind of extreme event and in any part of the world. We use the calibrated adaptation model to investigate how hazard expectations impact adaptation in the case of changes in frequency and severity of future events. Similarly, we use the adaptation model to investigate realistic scenarios of adaptation until the end of this century.

We conclude by discussing how hazard expectations could be the focus of public policies aimed at supporting adaptation in local communities, with a focus on how identification of factors to effectively support adaptation is now of utmost importance $[34,35]$. Finally, we point out how, in addition to several other positive impacts (e.g., scientific 
advancements in the fields of climate change, weather and climate extremes, and human systems impacts), vulnerability and adaptation analyses provide an invaluable contribution to human systems facing unprecedented climatic and weather challenges of the future $[36,37]$.

\section{Materials and Methods}

\subsection{Data Sources and Scales}

The hazard data we use to develop our adaptation model refer spatially to 395,526 U.S. Census blocks that intersect the CRB (Figure 1). These blocks belong to seven different U.S. states and 89 counties, as presented in Figure 2. In comparison to larger administrative spatial units (i.e., counties), which are usually the ones referred to in the literature, Census blocks provide an increased level of precision for the identification and prediction of extremes and for the attribution of damage. Summary statistics for the different possible spatial scales of administrative units intersecting CRB are presented in Table 1. Census blocks considered have an average size of about $2 \mathrm{~km}^{2}$ and a median area of only $0.04 \mathrm{~km}^{2}$.

Our economic model is calibrated using data for the 1997-2017 (current) period. The hazard data we use for analyzing paste hazard expectations extend from 1977 to 2017. Future scenarios use hazard and damage data predicted for the period 2018-2100. The data we use are scaled to quarterly time intervals.

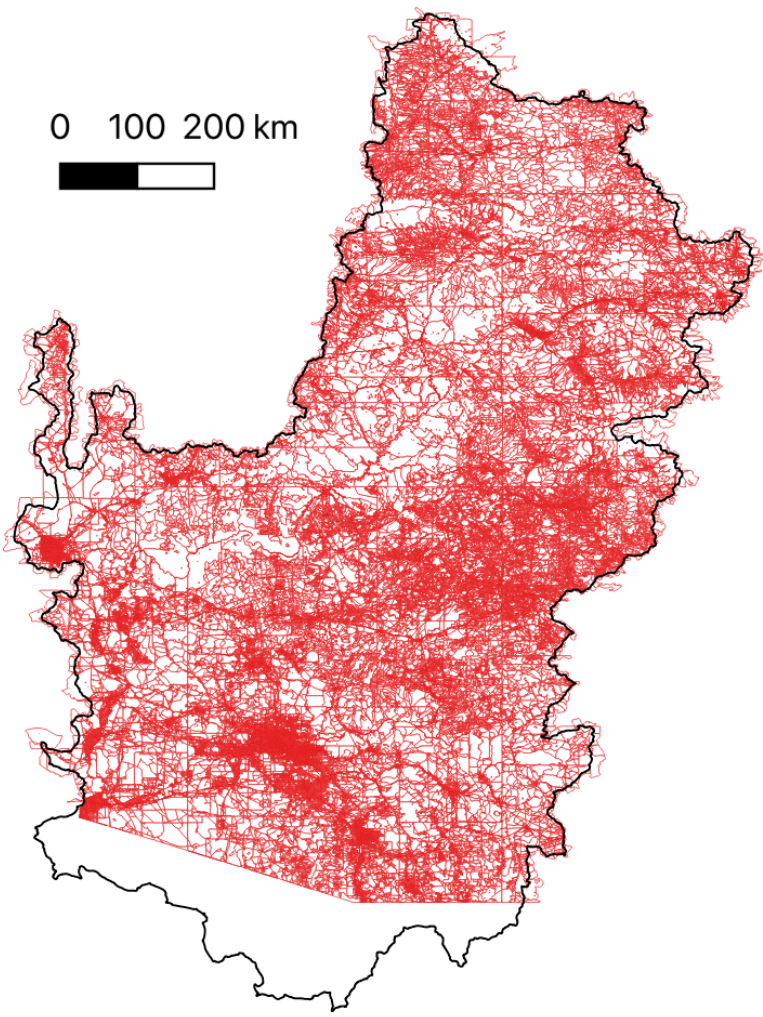

Figure 1. U.S. Census blocks in the Colorado river basin. The 395,526 U.S. Census blocks (represented in red) intersecting CRB (represented in black-U.S. Census 2010 boundaries [38]).

Table 1. Summary statistics for main U.S. Census units intersecting the CRB (areas in $\mathrm{km}^{2}$ ).

\begin{tabular}{lrrrr}
\hline Type of Unit & Number & Average Area & Area S. D. & Median Area \\
\hline States & 7 & $289,840.90$ & $59,742.19$ & $284,331.90$ \\
Counties & 89 & $11,213.40$ & $10,399.06$ & 8394.01 \\
Blocks & 395,526 & 2.18 & 19.57 & 0.04 \\
\hline
\end{tabular}




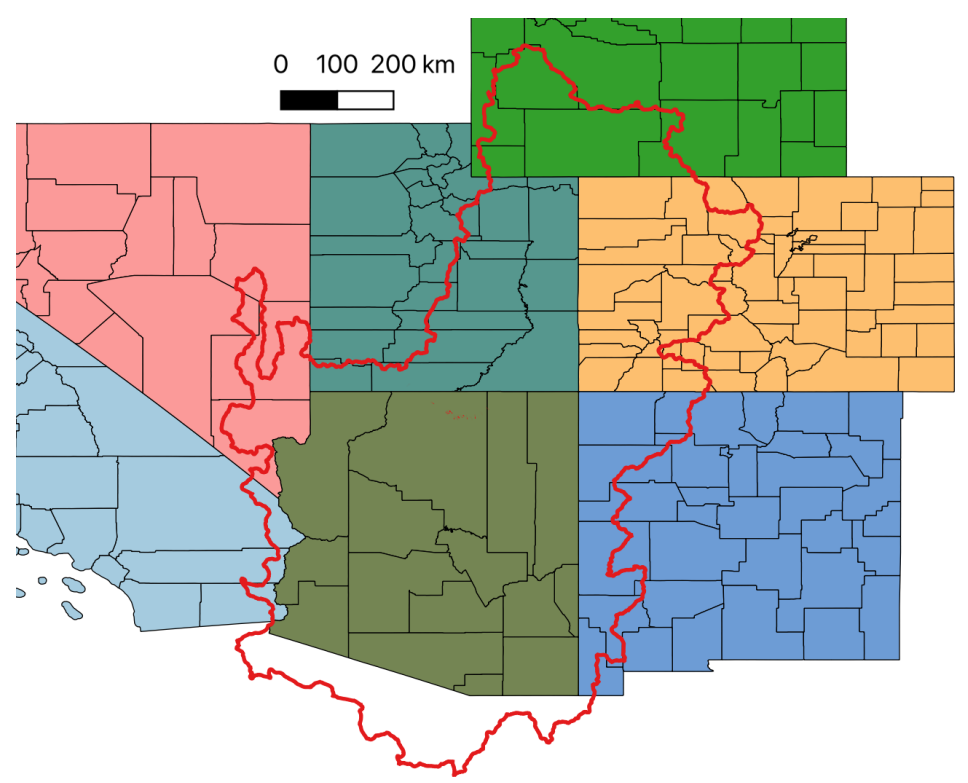

Figure 2. The Colorado river basin and main human scales. U.S. Census counties (represented in black) and states (from left to right, from bottom to top: California in light blue, Arizona in olive, New Mexico in blue, Nevada in pink, Utah in dark green, Colorado in orange, and Wyoming in green) intersecting CRB (represented in red-U.S. Census 2010 boundaries [38]).

\subsubsection{Hazard}

A natural hazard value is a quantification of the intensity of the extreme considered. Here, we define hazards using the concurrent estimation of multiple indicators of extreme events for flooding. All data are derived from simulations using the Variable Infiltration Capacity (VIC) hydrologic model [39], which is implemented as described in Bennett et al. [30]. VIC forcing data (i.e., temperature, precipitation, and wind speed) for historical simulations are generated from historical gridded climate data [40], while future climate data are generated from downscaled projections from the Multivariate Adaptive Constructed Analogue (MACA) database [41]. VIC parameters (i.e., soils, vegetation, and topography) are described in detail in Bennett et al. [30]. VIC is calibrated using a multiobjective, automated calibration tool to naturalized streamflow for select locations throughout CRB [30,42].

For this work, we used synoptic time scale (maximum daily values extracted for 5 days periods, with 73 5-day intervals in each year) data for each of three extreme flooding indicators following the work described in Bennett et al. [29]: maximum soil moisture in the entire soil column, maximum precipitation, and maximum runoff. We consider a historical period (1970-1999) along with current (2000-2017) and multiple future scenarios for different times (2020-2039, 2040-2069, and 2070-2099).

Historical and future scenarios are based on results from three different Earth System Models (ESMs): IPSL-CM5A-LR, GFDL-ESM2G, and MIROC-ESM. These three ESMs are selected as they represented a range of moderate 2040-2069 conditions (calculated as a difference from the 1970-1999 period) for CRB across the ESMs available in the MACA data set. Figure 3 illustrates 2040-2069 and 2070-2099 periods for all ESMs available in MACA. ESMs selected for this work include a warm/dry scenario (IPSL-CM5A-LR) and two moderately wet scenarios (warm/wet, GFDL-ESM2G and hot/wet, MIROC-ESM, Table S1). It is worth noting that IPSL-CM5A-LR tends towards drier and hotter, while the other two ESMs remain in the moderate warm/hot and wet range of the ESMs towards the end of the century, which has implications for the flooding results presented herein. 


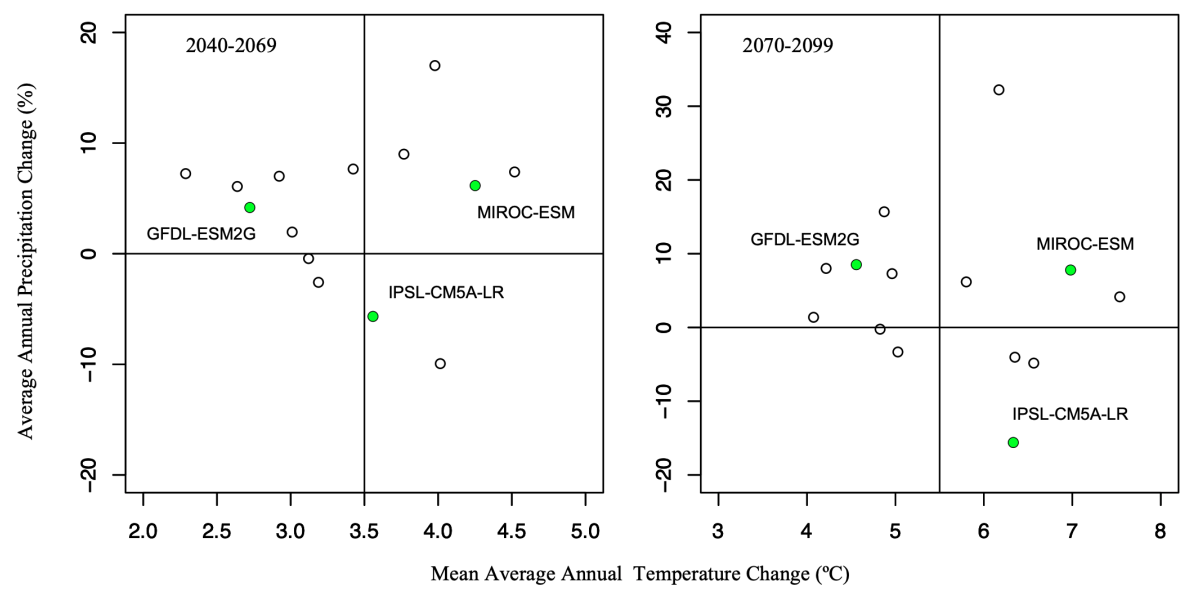

Figure 3. Annual average range of temperature in ${ }^{\circ} \mathrm{C}$ and precipitation in percentage values for two time periods for the three ESM selected for study calculated based on the difference from the historical period (1970-1999).

Synoptic data are spatially averaged for each Natural Resource Counsel (NRCS), United States Department of Agriculture (USDA) hydrological cataloguing unit, level eight (HUC8) watersheds for the CRB (134 total). Figure 4 illustrates spatially averaged synoptic data for each flooding indicator for a single HUC8 watershed: the Uncompahgre River basin. Concurrent copulas are calculated using the three flooding indicators following methods described below for each of the HUC8 basins, based on historical VIC simulation.
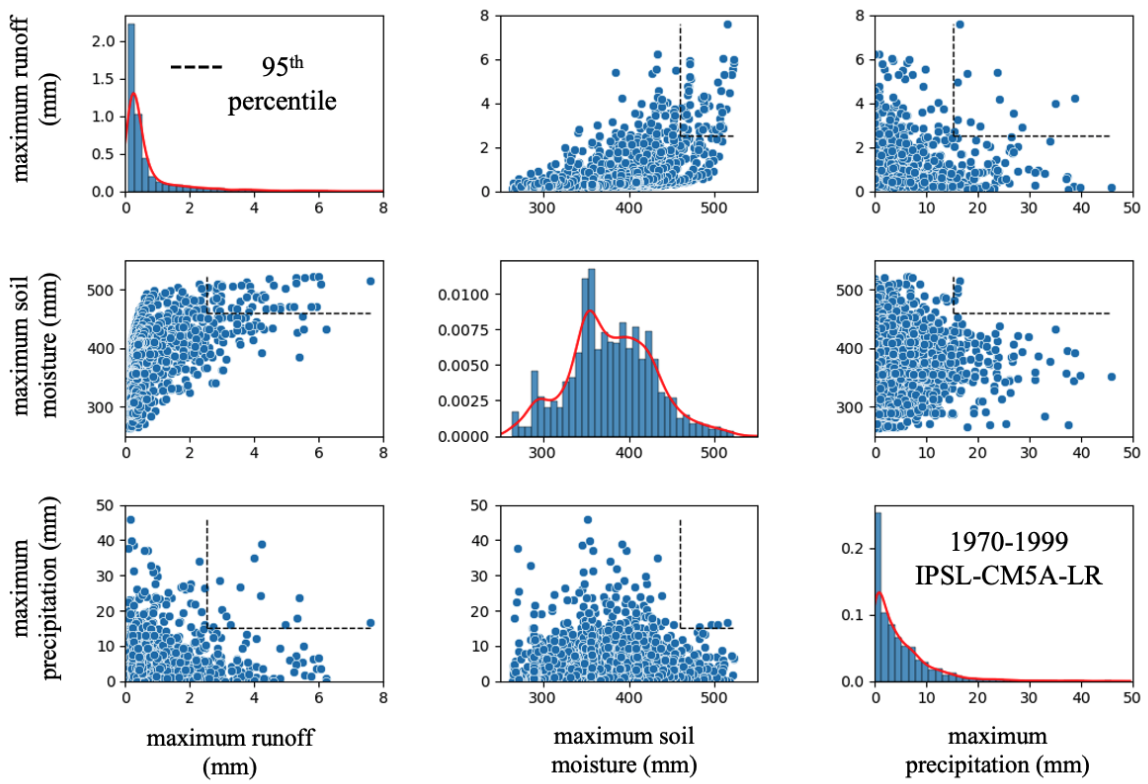

Figure 4. Input values to the copulas for the historical synoptic time series of maximum precipitation (precx, mm), maximum soil moisture (soilmx, mm), and maximum streamflow ( $\mathrm{qx}, \mathrm{mm}$ ) for IPSLCM5A-LR ESM for the Uncompahgre River basin in the Upper Colorado. The 95th percentile of the values is illustrated with dashed lines. Histograms show the distribution of the raw data values with lines for marginal fits.

The multidimensional representation of the joint distributions of relevant hydrological climate impacts is based on the concept of statistical copulas [43]. If $\mathbf{X}$ is a random vector of $m$ random variables $X_{1, \ldots, m}$ (e.g., streamflow, temperature, and evapotranspiration), the copula $\left(C_{\mathbf{X}}\right)$ gives their joint distribution according to the following (Sklar's theorem): 


$$
F_{\mathbf{X}}(\mathbf{x})=C_{\mathbf{X}}\left(F_{X_{1}}\left(x_{1}\right), \ldots, F_{X_{m}}\left(x_{m}\right)\right)
$$

where the $F_{X_{1}}\left(x_{1}\right), \ldots, F_{X_{m}}\left(x_{m}\right)$ functions are the marginal cumulative distribution functions of the individual variables, and $C_{\mathbf{X}}:[0,1]_{1} \times \cdots \times[0,1]_{m} \rightarrow[0,1]$.

The estimation of the concurrent distribution consists of finding a suitable multidimensional representation of (possibly) correlated data. The process of finding such representation takes place in two stages. The marginal univariate distributions for each individual variable is found, and the best model is chosen from goodness of fit (gof) tests by scaling and transforming raw data values as needed (see Figure 4). We use the R package fitdistrplus, which supports a number of probability distributions such as normal, gamma, normal, log-normal, exponential, gumbel, and beta. The 'fitdist' function is applied to fit the data, and 'gofstat' is used to perform gof tests. Then, we obtain the joint distribution by fitting a copula to the selected marginal distributions.

Copulas are selected from two popular copula families that included Elliptical copulas, which are restricted to radial symmetries and a more flexible family called Archimedean copulas. Typical Elliptical copulas include Gaussian and t-student copulas. Among the Archimedean copulas, the most common are Clayton, Frank, Gumbel, and Joe. To select the final copulas to represent flooding across the three dimensions, we iterate through a series of copulas to find the best fit using a quasi-Newton method [44].

Concurrent extremes values are transformed both spatially and temporally to match the scale of the adaptation model data. We first disaggregate copula results within the 95th percentile of the copula's range and then identify when these ranges were met or exceeded in the current and future data at the grid cell scale. This results in a conservative estimate of the changes in extremes, which we felt was most prudent provided the range of uncertainties present within the range of ESM estimates [45]. Then, we use spatial boundaries defining the U.S. Census blocks to query grid-cell scale copula results and select the spatial cells intersecting each block. As a last step, we compute the average value of flooding in those cells for each quarter considered. The final data set contains an average value of floodings for each block, quarter, and ESM considered. Copula results for the historical and future for the Uncompaghre River basin are shown as an example in Figure 5.

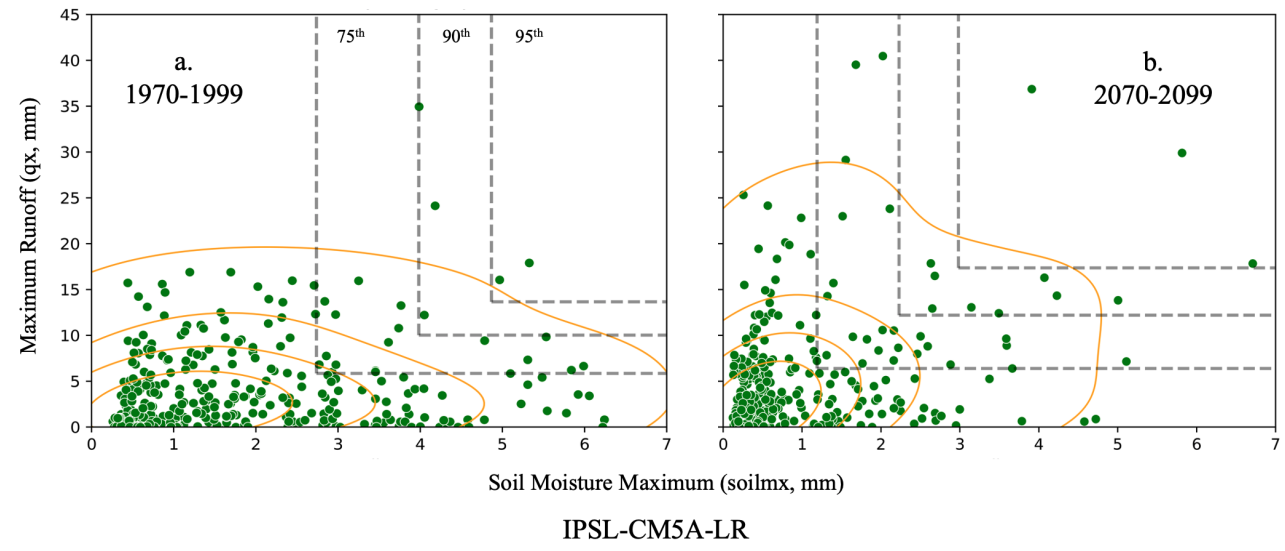

Figure 5. Historical (a) and future (b) copula for high precipitation ( $>1$ of standard deviation) plotted as soil moisture maximum against maximum runoff for the Uncompaghre River basin. Darker colors indicate a higher density of data. Dashed lines show 95th, 90th, and 75th percentiles of the data.

\subsubsection{Exposure}

Exposure refers to the monetary value of human assets and activities present in a specific space and time. Several different approaches can be adopted for quantifying exposure. Here, we follow the most common choice in the literature (e.g., [20,21,46]) by applying the use of the gross domestic product (GDP). GDP represents the level of human 
activities in a period. Furthermore, by including the added value contribution by the capital factor, GDP also captures the level of the stock of assets present in the area.

GDP is not readily available at the scales of Census blocks and for quarterly time intervals. We, thus, compute county level quarterly GDP values as in [47] for each 2-digit NAICS industry. The counties considered are the ones intersecting CRB as in Figure 2. We divide the GDP industry-level value by the number of jobs in the corresponding industry obtaining a GDP value per job of each industry in each county. We obtained the block level total GDP by multiplying those numbers with job information at the 2-digit NAICS that is reported in the workspace characteristic data (WAC) of Longitudinal EmployerHousehold Dynamics (LEHD) Origin-Destination Employment Statistics (LODES) database administered by the U.S. Census. The time intervals in the period 1997-2017 that are not provided by LODES have been estimated by linearly extrapolating the jobs series for each block and industry.

When running future scenarios, we keep exposure constant and equal to the values observed in each quarter and block of the last year of the calibration period, i.e., 2017. For instance, the exposure of block $b$ in the second quarter of 2078 will be as the GDP in the same block in the second quarter of 2017. In this manner and by using exposure values at 2017 prices as obtained by correcting current values with the consumer price index (CPI) released by the Bureau of Labor Statistics (BLS), we keep prices constant for both model calibration and predictions.

\subsubsection{Damage}

We consider only the direct economic losses (DEL) that have been observed for events recorded in the Storms Events Database published by the National Centers for Environmental Information (NCEI) of the U.S. National Oceanic and Atmospheric Administration (NOAA).

We first split each event in the Storm Events Database to blocks and quarters as follows. From the temporal perspective, we proportionally distribute the events according to the their start and end tine to single or multiple quarters. From the spatial perspective, we use the latitude and longitude of extent of each event to split it evenly across the blocks intersected by the event.

The value of damage distributed to blocks and quarters either proportionally or evenly is computed as the sum of damage to crops, properties, and people. Damage to properties and crops are used as reported in the original database while injuries and fatalities are quantified as it follows. Fatalities are transformed in monetary values through the value of statistical life (VSL) as computed nationally by the U.S. Department of Transportation (DOT) based on income losses with elasticity as in [48] and personal income data published by the U.S. Bureau of Economic Analysis (BEA). Injuries are converted to monetary values by referring to moderate severity injuries that are valued at $4.7 \%$ of VSL. Damage values are reported at 2017 prices.

\subsection{Model calibration}

We use the dataset described above for the period 1997-2017 to calibrate the adaptation model. In particular, we consider only blocks where the considered exposure has been positive sometime in the period. Summary statistics of the calibration sample are reported in Table 2. 
Table 2. Summary statistics for calibration sample considered.

\begin{tabular}{lccccc}
\hline Variable & Obs. & Mean & S.D. & Minimum & Maximum \\
\hline $\begin{array}{l}\text { Hazard A } \\
\text { (GFDL-ESM2G) }\end{array}$ & 331,560 & 2.24 & 5.81 & 0 & 54 \\
$\begin{array}{l}\text { Hazard B } \\
\text { (IPSL-CM5A-LR) }\end{array}$ & 331,560 & 1.30 & 3.66 & 0 & 57 \\
$\begin{array}{l}\text { Hazard C } \\
\text { (MIROC-ESM) }\end{array}$ & 331,560 & 0.47 & 2.17 & 0 & 54 \\
$\begin{array}{l}\text { Exposure } \\
\text { (MUSD - 2017 prices) }\end{array}$ & 331,560 & 6.43 & 34.60 & 0 & 2690 \\
$\begin{array}{l}\text { Damage } \\
\text { (USD-2017 prices) }\end{array}$ & 331,560 & 27.89 & 7619.99 & 0 & $3,491,619$ \\
\hline
\end{tabular}

Following recent empirical modeling approaches [19-21,49] to the adaptation to climate disasters and extremes, we calibrate the adaptation model by using count variables regression approaches and accounting for statistical over dispersion in the data. In particular, we fit a zero-inflated negative binomial (ZINB) model to overdispersed count data with excess zero counts. The ZINB model assumes that the excess zero counts come from a logit model and the remaining counts come from a negative binomial model. The probability distribution of the ZINB random variable can be expressed as follows:

$$
y_{i} \sim \begin{cases}0 & \text { with probability } p_{i} \\ N B\left(\mu_{i}, \Theta\right) & \text { with probability } 1-p_{i}\end{cases}
$$

where $y_{i}$ is our dependent count variable that is the non-negative value in dollars of damage in a block, and $\Theta$ is the dispersion parameter (the estimate of this parameter points to over-dispersion and, hence, here a negative binomial model is more appropriate than a Poisson model).

Hence, the regression models, without reporting error terms, are a negative binomial regression model for positive values of the count variable damage:

$$
\log \left(\mu_{i}\right)=\beta_{0}+\beta_{1} H_{i}+\beta_{2} X_{i}+\beta_{3} E[H]_{i}
$$

and a logit model to capture the zero inflation:

$$
\operatorname{logit}\left(p_{i}\right)=\gamma_{0}+\gamma_{1} H_{i}+\gamma_{2} X_{i}+\gamma_{3} E[H]_{i},
$$

where we consider the same covariates in both models (i.e., hazard- $H$, exposure- $X$, and hazard expectation $-E[H]$ ).

Estimates for $\beta, \gamma$, and $\Theta$ are obtained by maximizing the log-likelihood function.

$$
L(\beta, \gamma, \Theta \mid y, X)=\sum_{i=1}^{n} \log f\left(y_{i} \mid X_{i}, \beta, \gamma, \Theta\right) .
$$

We first select the hazard ESM that better fits the data. In fact, we run the estimation three times with different values of $H$ and $E[H]$, and in each run, we use the three different $H$ presented above (i.e., $\mathrm{A}, \mathrm{B}$, and $\mathrm{C}$ as in Table 2 ) and their corresponding moving average over the previous 20 years as $E[H]$ (i.e., for each block $b$ at time $t$, we have $E[H]_{b, t}=\sum_{l=1}^{L} H_{b, t-l}$, where $L=80$ are the quarters in the previous 20 years). We then select the joint hazard prediction between $\mathrm{A}, \mathrm{B}, \mathrm{C}$, and the average values obtained from linearly composing three ESMs and all the possible couples of them with respect to $H$ and $E[H]$ that maximizes the log likelihood value computed as in Equation (5). The selected $\mathrm{ESM}$ is $\mathrm{B}$, i.e., the IPSL-CM5A-LR.

Second, we fit the model by obtaining the estimates reported in Table 3. Values reported in Table 3 should be interpreted as incident rate ratios (IRR) and odds ratios and 
the constant reports the baseline IRR and odds ratio. Increases in probabilities reported for covariates in the binomial model refer to increases in the positive value of the dependent variable (i.e., damage). Similar increases in the logit model refer to the zero-inflation model and, thus, refer to increases in probabilities to obtain zero-value damage. Results not reported here confirmed the need for modeling zero inflation and for choosing a ZINB model over a zero inflated Poisson (ZIP) model.

Table 3. Adaptation model calibration: zero-inflated negative binomial estimates of flooding damage (USD) in the CRB 1997-2017 (monetary values in 2017 prices).

\begin{tabular}{ll}
\hline Negative Binomial & IRR (Std. Err.) \\
\hline Hazard $(H)$ & $0.977(0.056)$ \\
Exposure $(X)$ & $1.000^{* * *}(0.000)$ \\
Hazard Expectation $(E[H])$ & $0.325(0.258)$ \\
Constant & $170,153.8^{* * *}(56,058.52)$ \\
\hline Inflation Model (Logit) & Odds Ratio (Std. Err.) \\
\hline Hazard $(H)$ & $0.939^{* * *}(1.019)$ \\
Exposure $(X)$ & $1.000^{* *}(1.000)$ \\
Hazard Expectation $(E[H])$ & $1.657^{*}(1.355)$ \\
Constant & $4081.558(1.168) * * *$ \\
\hline Observations & 331,560 \\
Log likelihood & -1464.048 \\
\hline Note: Significant at ${ }^{* * *} 0.01, * * 0.05$, and $* 0.10$ level. &
\end{tabular}

Odds ratios and IRRs in Table 3 and the coefficients derived largely confirm theoretical model predictions. First, in the inflation model, the probability of having no damage is negatively correlated with $H$ and $X$ and positively with $E[H]$. Second, in the negative binomial model, $E[H]$ is negatively correlated with damage. In this latter model, the significant coefficient of $X$ has the opposite direction of what is predicted by the theory, and this could be interpreted from a two-fold perspective. First, the total impact is on the right direction since the inflation model coefficient is larger. Second, this could be explained as further evidence in favor of larger preferences for safety by wealthier communities, as found in many empirical works ( e.g., the inverted u-shape damage function in [20]).

\section{Results and Discussion}

\subsection{Floodings as Concurrent Extremes}

Copulas provide a means to represent future concurrency of the types of events that can result in flooding, such as maximum soil moisture, runoff, and precipitation, as applied in this work. However, copulas as a tool are difficult to apply when attempting to link results to actual occurrences of events. For instance, direct comparisons to flooding values in the CRB are next to impossible given the rare nature of events, and the variability of these events within the historical record. Hydrologic models, such as VIC, when coupled with ESMs, provide us a tool to examine future changes, but they are less than ideal to consider current and near-term events; thus, this is a limitation of the work presented herein.

Despite the uncertainties associated with the use of copulas, we can use copulas to detect flooding occurrences in historical and future records and discuss the changes and variability over time. Average future values of flooding hazards until 2100 are reported for the IPSL-CM5A-LR ESM, which was chosen as the best fit to historical data in calibration (Figure 6). This ESM is also one of the driest scenarios for CRB; thus, our results represent a moderate extrapolation of flooding risks under future climate change in the CRB.

Counts of flooding instances across the entire CRB (grid cells) for each ESM are provided in the Supplemental Materials (Figure S1) and coincide with the average level of natural hazards shown here. Flooding instances are low throughout the 2020-2040s, and then it rises after 2040 to a peak in 2060 to 2080s and are generally lower after the 
2080s, coinciding with a decrease in snow in the basin (e.g., [50]). IPSL-CM5A-LR ESM, as the driest of all ESMs, has the lowest number of flooding occurrences (maximum value of 123), with 159 months with flooding events occurring in them over the entire record. MIROC-ESM, the hot/wet ESM, has the highest number of flooding occurrences (256), while the warm/wet ESM, GFDL-ESM2G, is in between the two in terms of the number of occurrences (185). On the other hand, both GFDL-ESM2G and MIROC-ESM contain the same number of flooding months, 179, only 20 more than IPSL-CM5A-LR. GFDL-ESM2G tends to have more flooding occurrences after the 2060s, and even IPSL-CM5A-LR appears to have a final spike in the record right before the end of the century.

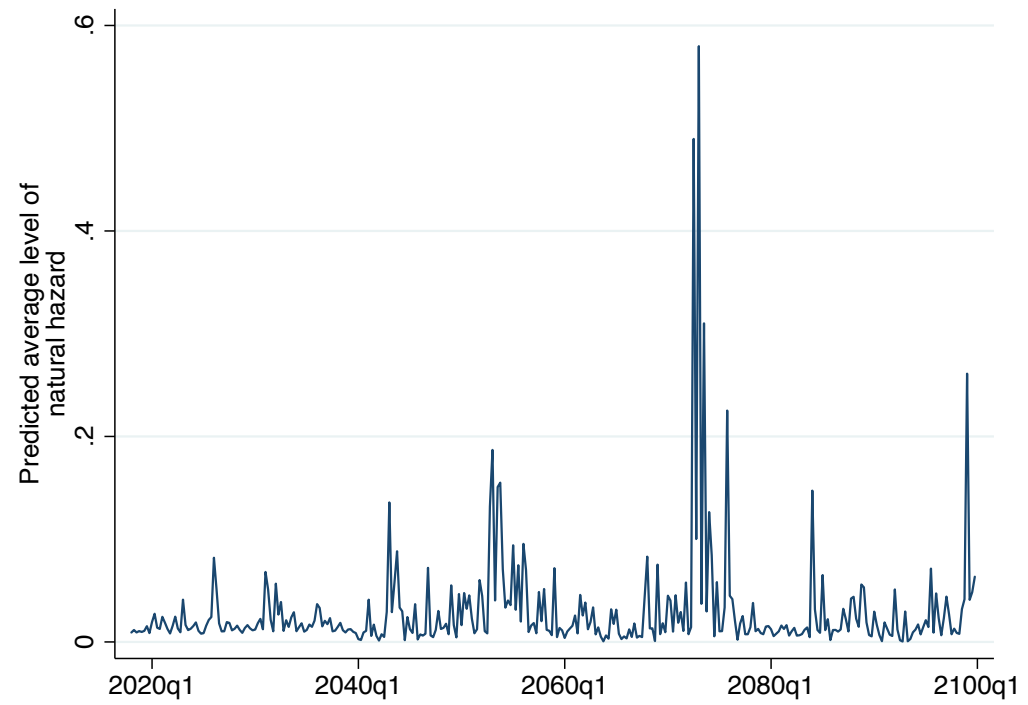

Figure 6. Quarterly level of flooding hazard as the predicted average levels in CRB Census blocks until 2100. Predictions based on IPSL-CM5A-LR ESM.

Results about floodings as concurrent extremes point out that, overall, flooding is highly variable, likely owing to the competing nature of increasing precipitation and decreasing snow, with steadily increasing temperatures, under future climate scenarios. The results are consistent with main outcomes of contributions using similar approaches applied to different regions and based on different ESMs [51,52].

\subsection{Adaptation Model}

Modeling adaptation as an investment problem means identifying three main variables of interest. The first one is the natural hazard $H$, which is to say a quantification of intensity and frequency of extremes. The second one is exposure $X$, which is a single monetary value that represents all human assets and activities at stake. Finally, there is damage $D$, which is the monetary value of human assets and activities that are lost because of the occurrence of natural hazards.

The adaptation model assumes that $D$ is a positive function of both $H$ and $X$ and that the difference between a more adapted system and a less adapted one is that facing the same levels of $X$ and $H$ where the former has a lower $D$ than the latter. Furthermore, while economic theory tells us that the optimal level of investment in adaptation is the one where the adaptation marginal benefit equals its marginal cost [53], such theoretical predictions are currently difficult to use for local communities and policies since we neither have means to effectively measure the quantity of adaptation nor its cost function (benefits could be measured as decreases on predicted $D$ levels, which is to say as avoided losses).

Given the difficult applicability of theoretical results, here we improve the adaptation model by adding a fourth variable $E[H]$, which is the expected level of natural hazards. Expected hazard drives the assessment of future potential damage and, hence, of the 
future benefits of adaptation investments. Expected hazard should, thus, be negatively correlated with $D$. Our resulting model is, thus, $D=f\left(\begin{array}{ccc}H & X & E[H] \\ + & + & -\end{array}\right)$. The analysis in [21] demonstrated how, consistently with the adaptation model based on investment choices, expectations about future exposure $E[X]$ are also negatively correlated with $D$. Here, another type of expectation that could be used for policy making and that supports the positive role and impacts of scientific research on climate change is investigated.

Results of our model calibration for the CRB over the period 1997-2017 (see details in Section 2) are largely consistent with theoretical predictions. Using these results, we can examine the empirically calibrated model by predicting $D$ over $H$ and considering different levels of $E[H]$ and $X$ as observed on average across CRB blocks in 2017. Predicted quarterly levels of damage are presented in Figure 7 for increasing levels of $H$ on a logarithmic scale and up to the maximum level observed in a single CRB block (i.e., $H=57$ ).

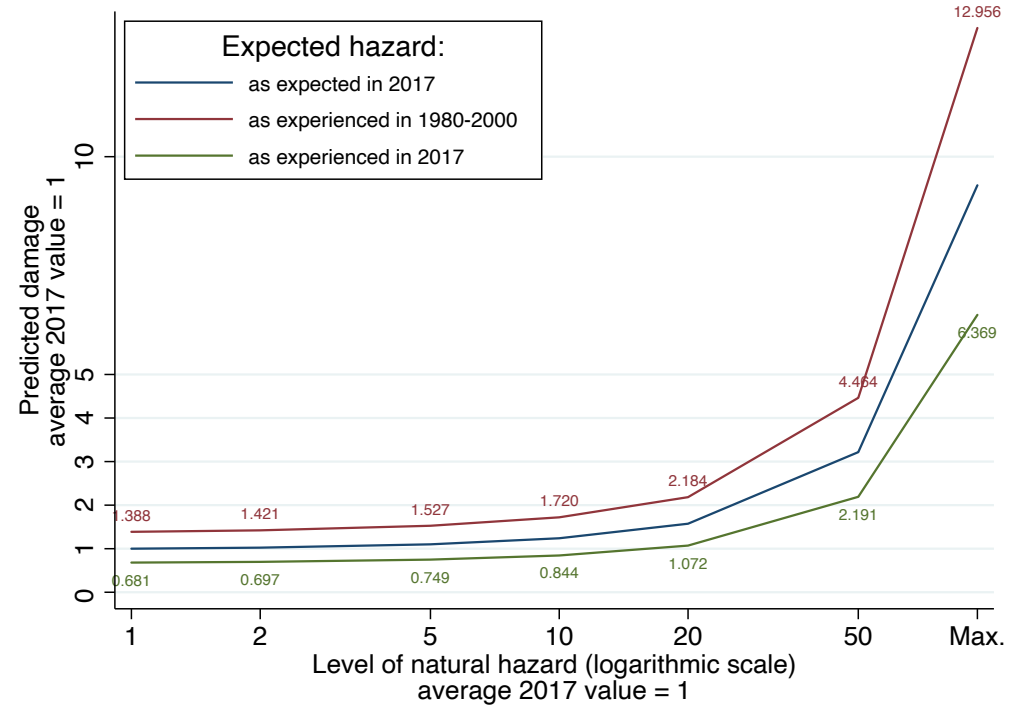

Figure 7. Adaptation model results. Predicted damage over levels of natural hazard (flooding) and scenarios of hazard expectations (average 2017 damage $D$ and hazard $H=1$ ) with constant exposure (exposure $X=$ average 2017 value).

The three different levels of $E[H]$ tells us different things. One scenario, represented as a green line, represents the expectation of future $H$ as observed on average in 2017 (i.e., $H=0.6)$. A second scenario (blue line) is to have expectations as those calibrated in $2017(E[H]=0.365)$, which is the quarterly mean across blocks of the moving average of $H$ over the previous 20 years. Finally, the red line illustrates the results for hazard expectations equal to the average $H$ experienced in the last two decades of the last century $(E[H]=0.164)$. The three scenarios represent three hypotheses of decreasing speed in the process by which local communities adapt their expectations about the future to a changing climate and associated changing levels of natural hazard.

Results highlight that communities that are capable of updating their expectations of natural hazards to levels recently experienced can adapt more, up to the point where they can tolerate much more natural hazards than others. For instance, this is confirmed by looking at the very similar $D$ obtained when comparing the red-line scenario (i.e., $E[H]=H$ as in 1980-2000) for $H=20$ and the green-line scenario (i.e., $E[H]=H$ as in 2017) for $H=50$. By keeping constant the human assets and activities at stake, future damage levels can be up to 12-times what was observed in 2017, confirming to a large extent results obtained with other approaches [54-56]. However, we can now add that this is true only if more severe hazards are not expected and that actually expectations have the potential to offset the adverse impacts of a changing climate through adaptation. 


\subsection{Scenarios Until the End of the Century}

We use predictions about flooding hazards in CRB until the end of this century to study three scenarios of $E[H]$ designed above to investigate the impact on adaptation of quickly updating hazard expectations. In particular, we consider a scenario of a constant level of $E[H]$ equal to the average $H$ experienced by each block in the 1980-2000 period. Second, we investigate a dynamic scenario where $E[H]$ is updated in each block at the beginning of a new decade by using the average value of the experienced $H$ in the two previous decades. Finally, we introduce a scenario in which the hazard expectation is also partially influenced by scientific predictions of natural hazard levels. In this scenario, at the beginning of each decade, $E[H]$ in each block is updated to be equal to the average actual $H$ in the last decade and the one correctly predicted for the current decade.

We run the adaptation model in each CRB block quarterly obtaining results as in Figure 8 . The figure confirms most of the dynamics suggested by $H$ predictions (see also Figure 6) and points out that up-to-date $E[H]$ lower predicted damage even in periods of relatively low levels of natural hazard (see, for instance, the difference between the blue line and the others in the years before 2040).

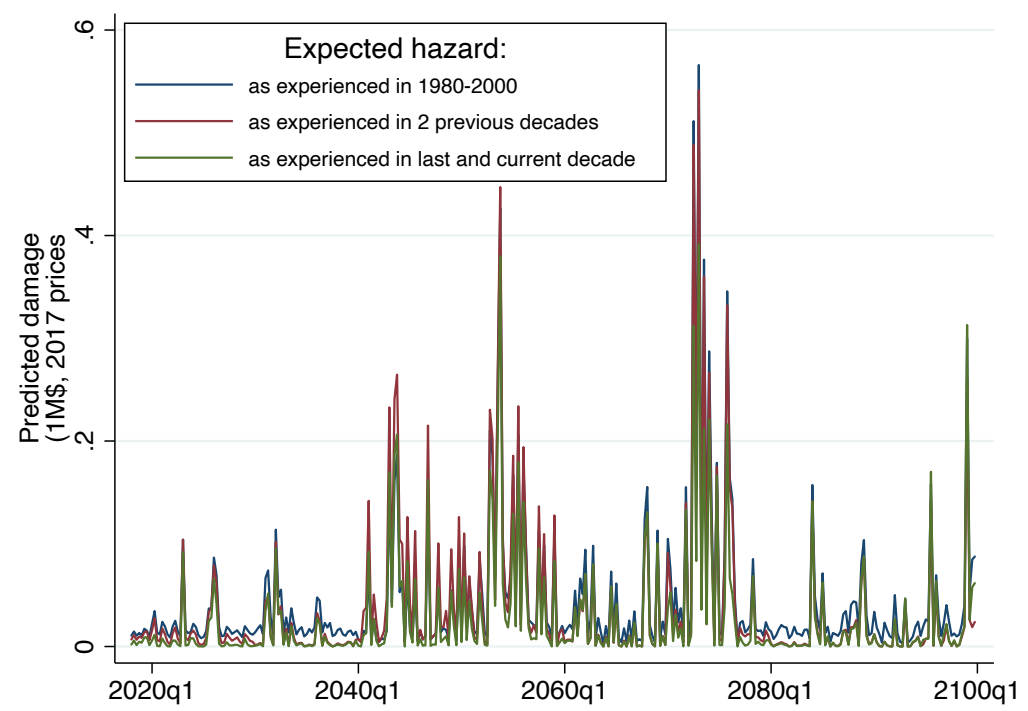

Figure 8. Quarterly flooding damage until 2099 in CRB. Predicted average levels in census blocks by hazard expectation scenario.

Furthermore, we remove seasonal dynamics by aggregating predictions in annual levels and we present them in Figure 9 as the decadal mean and 95\% confidence intervals to compare future scenarios with predicted and observed levels in the adaptation model calibration period 1997-2017 (the 21-year long calibration period is reported at the beginning of the horizontal axis of the figure).

As noted previously, updating hazard expectations continuously improves adaptation (i.e., reduces predicted damage) even when hazard levels are relatively low (see for instance decades starting in 2020, 2030, 2060, and 2080). Furthermore, updating expectation by including also predictions for the hazard in the current period strongly improves adaptation in particular in periods when natural hazards are at peak levels. The generic adaption model (and with other approaches such as those reported in [54-56]) results are confirmed by fine-scale predictions of the CRB for the remainder of this century. In terms of the size of what can be gained by using up-to-date and even forward-looking $E[H]$, values such as those in the 2070-2079 decade point out that the decrease in predicted damage can be large and, on average, even half of the total experienced in 1997-2017 and in some years even four or five times that value. 


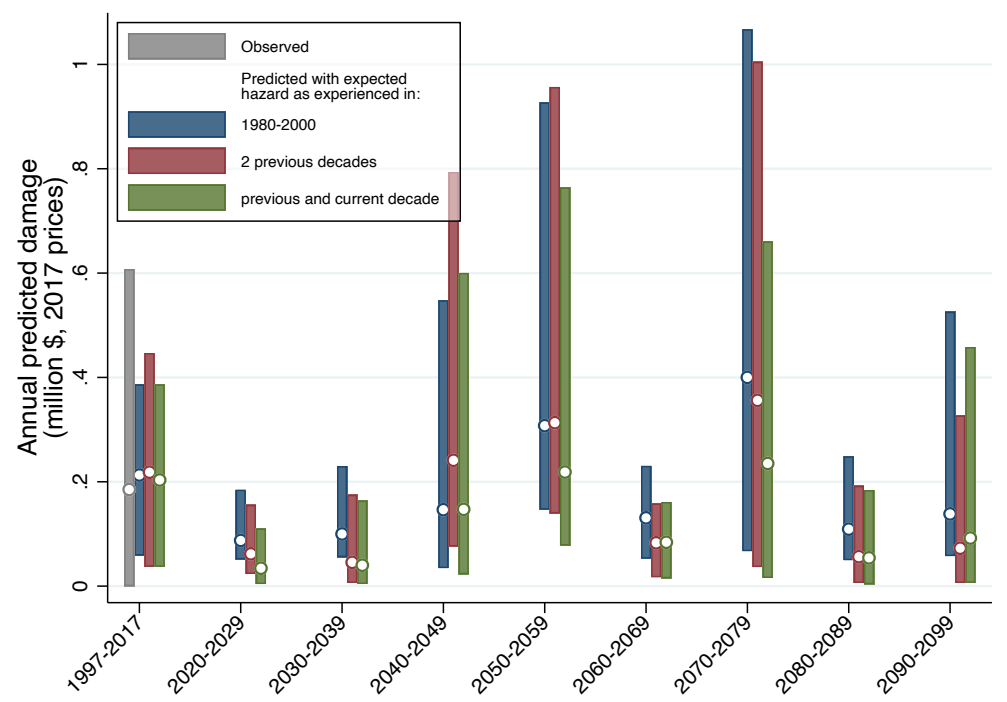

Figure 9. Annual flooding damage from 1997 to 2099 in the CRB. Observed and predicted damage in census blocks. Average levels and 95\% confidence intervals computed over adaptation model calibration period, decades, and hazard expectation scenarios.

\section{Conclusions}

We show here how to model the endogenous process of human adaptation to extremes as an investment decision. We apply the approach to flooding in the U.S. Colorado River basin, developing and adapting the data and approaches needed, such as the one considering the concurrent distribution of several variables for the quantification and prediction of climate extremes. Our approach is independent of the geographical area and the extreme event considered in this work. The method can be replicated on other areas in the world and focuses on different kinds of extremes (e.g., droughts, wildfires, snow and ice storms, tornadoes, etc.).

Results from both the theoretical (but empirically calibrated) model and from a fine scale model studying future predicted extremes up to 2100 show that hazard expectation has the potential to offset adverse changes in damages due to a changing climate [22]. We use the driest ESM (i.e., IPSL-CM5A-LR); thus, our results are robust even under the lowest future flooding projection. Changes in future damage due to hazard expectations are significant even though changes in extremes are conservative. The findings presented in [21] show how expectations about future exposure can shape adaptation. Expectations about the future (either about future exposure or future hazard) are, thus, a predominant factor in adaptation choices by human systems, and these choices can be studied as investments aimed at managing future risks.

Our results also indicate that the speed by which local communities adapt their expectations about the future to a changing climate and associated changing levels of natural hazard is key in managing future risks. Recent empirical studies in the same area $[57,58]$ have pointed out how the speed of expectation update is strongly correlated with historical experience. Communities that have faced the most adversities most recently are the quickest to update their beliefs about a different future. We can conclude that particular attention should be spent on communities that, by chance, have not experienced major recent extremes or that have experienced a recent sharp increase in exposure because they are not only the ones most likely to have erroneous expectations about future natural risks but also the ones that are the slowest in updating them.

Modeling human systems adaptation to extremes as an investment choice effectively captures main variables and dynamics at work and allows us to quantify the impact of hazard expectations [19-21]. This variable influences today's investments in adaptation by defining their future benefits, and as such plays a critical role in adaptation that calls 
for quantification and accurate modeling. The research supports the use of expectations as key policy lever for adaptation. Effective adaptation strategies could be based on assessing losses potentially caused by future natural hazards. Local communities would, thus, be allowed to fully understand the risk posed by climate change. Updating community beliefs is a complex learning process that can be supported by public policies [59-61].

In this context, scientific credibility is also extremely important because risk assessment for the future must be trustworthy in order to be accepted and used by society. In fact, scientific predictions are often difficult to be effectively incorporated by public policies in particular when they are derived from advanced but complicated models, which are difficult to be explained and trusted [62]. Science reputation is key for acceptance [63-65] and for protecting communities through the adaptation mechanism investigated here. In order to establish and maintain scientific credibility, society has to invest in particular to advanced prediction accuracy. Our results, thus, suggest a positive benefit of public investments in climate impacts studies on human systems. Good science makes human systems adaptation possible and effective.

Supplementary Materials: The following supporting information can be downloaded at the following: https:/ /www.mdpi.com/article/10.3390/cli10020027/s1, Table S1: Annual average range of temperature $\left({ }^{\circ} \mathrm{C}\right)$ and precipitation (\%) values for two time periods for the three ESMs selected for study, calculated based on the difference from the historical period (1970-1999); Figure S1: Flooding occurrences as counts of flooding events for all grid cells across CRB. Each of three ESMs are shown, the driest ESM (IPSL-CM5A-LR) that is the focus of the main body of the work, the warm/wet ESM (GFDL-ESM2G), and the hot/wet ESM (MIROC-ESM). Grey lines show the 2000, 2030, and 2070 to align with periods of time presented in the paper.

Author Contributions: R.B. and K.E.B. developed the idea for the paper. K.E.B. and C.J.T. developed concurrent extreme methodology and data. R.B. scaled all data sets, developed and fitted the adaptation model, and analyzed results. R.B., K.E.B., C.J.T. and J.A.O. conducted the literature search and wrote the paper. All authors have read and agreed to the published version of the manuscript.

Funding: This work was funded under the Los Alamos National Laboratory Lab Directed Research and Development (LDRD) Early Career Research program (20180621ECR). VIC modeling work that our analysis is based on was completed under Los Alamos Director's Postdoctoral Fellowship, 20160654PRD (KB).

Institutional Review Board Statement: Not applicable.

Informed Consent Statement: Not applicable.

Data Availability Statement: Most of the data referred to in Section 2.1 are freely available online. Downscaled CMIP5 climate model projections may be downloaded via the MACA web portal: https:/ / climate.northwestknowledge.net/MACA/ (accessed on 9 January 2021). VIC model may be downloaded via GitHub: https://github.com/UW-Hydro/VIC (accessed on 9 January 2021). Historical VIC forcing data may be obtained from ftp:/ / gdo-dcp.ucllnl.org/pub/dcp/archive/OBS/ livneh2014.1_16deg/ (accessed on 9 January 2021). Other parameter files and model outputs may be obtained by contacting the authors. All other data, adaptation model, and code that support the findings of this study are available from the corresponding authors upon reasonable request.

Acknowledgments: We thank Jorge Urrego Blanco for developing the initial code and contributing to early discussions around this work.

Conflicts of Interest: The authors declare no conflict of interest.

\section{References}

1. McCarthy, J.J.; Canziani, O.F.; Leary, N.A.; Dokken, D.J.; White, K.S. (Eds.) Climate Change 2001: Impacts, Adaptation, and Vulnerability: Contribution of Working Group II to the Third Assessment Report of the Intergovernmental Panel on Climate Change; Cambridge University Press: Cambridge, UK, 2001; Volume 2.

2. Adger, W.N. Scales of governance and environmental justice for adaptation and mitigation of climate change. J. Int. Dev. 2001, 13, 921-931. [CrossRef]

3. Adger, W.N.; Arnell, N.W.; Tompkins, E.L. Successful adaptation to climate change across scales. Glob. Environ. Chang. 2005, 15, 77-86. [CrossRef] 
4. Agrawal, A. The Role of Local Institutions in Adaptation to Climate Change; World Bank: Bretton Woods, NH, USA, 2008.

5. Agrawal, A. Local institutions and adaptation to climate change. Soc. Dimens. Clim. Chang. Equity Vulnerability A Warm. World 2010, 2, 173-178.

6. Carpenter, S.R.; Arrow, K.J.; Barrett, S.; Biggs, R.; Brock, W.A.; Crépin, A.S.; Engström, G.; Folke, C.; Hughes, T.P.; Kautsky, N.; et al. General resilience to cope with extreme events. Sustainability 2012, 4, 3248-3259. [CrossRef]

7. Zscheischler, J.; Westra, S.; Van Den Hurk, B.J.; Seneviratne, S.I.; Ward, P.J.; Pitman, A.; AghaKouchak, A.; Bresch, D.N.; Leonard, M.; Wahl, T.; et al. Future climate risk from compound events. Nat. Clim. Chang. 2018, 8, 469-477. [CrossRef]

8. Raymond, C.; Horton, R.M.; Zscheischler, J.; Martius, O.; AghaKouchak, A.; Balch, J.; Bowen, S.G.; Camargo, S.J.; Hess, J.; Kornhuber, K.; et al. Understanding and managing connected extreme events. Nat. Clim. Chang. 2020, 10, 611-621. [CrossRef]

9. Stott, P. How climate change affects extreme weather events. Science 2016, 352, 1517-1518. [CrossRef]

10. Chen, Y.; Moufouma-Okia, W.; Masson-Delmotte, V.; Zhai, P.; Pirani, A. Recent progress and emerging topics on weather and climate extremes since the fifth assessment report of the intergovernmental panel on climate change. Annu. Rev. Environ. Resour. 2018, 43, 35-59. [CrossRef]

11. Trenberth, K.E.; Fasullo, J.T.; Shepherd, T.G. Attribution of climate extreme events. Nat. Clim. Chang. 2015, 5, 725-730. [CrossRef]

12. National Academies of Sciences, Engineering, and Medicine. Attribution of Extreme Weather Events in the Context of Climate Change; National Academies Press: Washington, DC, USA, 2016.

13. Swain, D.L.; Singh, D.; Touma, D.; Diffenbaugh, N.S. Attributing extreme events to climate change: A new frontier in a warming world. One Earth 2020, 2, 522-527. [CrossRef]

14. Leonard, M.; Westra, S.; Phatak, A.; Lambert, M.; van den Hurk, B.; McInnes, K.; Risbey, J.; Schuster, S.; Jakob, D.; Stafford-Smith, M. A compound event framework for understanding extreme impacts. WIREs Clim. Chang. 2014, 5, 113-128. [CrossRef]

15. McPhillips, L.E.; Chang, H.; Chester, M.V.; Depietri, Y.; Friedman, E.; Grimm, N.B.; Kominoski, J.S.; McPhearson, T.; Méndez-Lázaro, P.; Rosi, E.J.; et al. Defining Extreme Events: A Cross-Disciplinary Review. Earth's Future 2018, 6, 441-455. [CrossRef]

16. Markandya, A.; Galarraga, I.; de Murieta, E.S. Routledge Handbook of the Economics of Climate Change Adaptation; Routledge: London, UK; New York, NY, USA, 2014.

17. Huggel, C.; Stone, D.; Auffhammer, M.; Hansen, G. Loss and damage attribution. Nat. Clim. Chang. 2013, 3, 694-696. [CrossRef]

18. Cardona, O.D.; Van Aalst, M.K.; Birkmann, J.; Fordham, M.; Mc Gregor, G.; Rosa, P.; Pulwarty, R.S.; Schipper, E.L.F.; Sinh, B.T.; Décamps, H.; et al. Determinants of risk: Exposure and vulnerability. In Managing the Risks of Extreme Events and Disasters to Advance Climate Change Adaptation: Special Report of the Intergovernmental Panel on Climate Change; Cambridge University Press: Cambridge, UK, 2012; pp. 65-108.

19. Schumacher, I.; Strobl, E. Economic Development and Losses Due to Natural Disasters: The Role of Risk; Working Paper Hal—00356286; HAL: Paris, France, 2008.

20. Schumacher, I.; Strobl, E. Economic development and losses due to natural disasters: The role of hazard exposure. Ecol. Econ. 2011, 72, 97-105. [CrossRef]

21. Boero, R.; Bianchini, L.; Pasqualini, D. Vulnerability and adaptation to severe weather events in the American southwest. Weather Clim. Extrem. 2015, 8, 12-25. [CrossRef]

22. Shrader, J. Expectations and Adaptation to Environmental Risks; University of California: Los Angeles, CA, USA, 2020; pp. 1-68; SSRN 3212073.

23. Osberghaus, D. The determinants of private flood mitigation measures in Germany-Evidence from a nationwide survey. Ecol. Econ. 2015, 110, 36-50. [CrossRef]

24. Wilby, R.L.; Keenan, R. Adapting to flood risk under climate change. Prog. Phys. Geogr. 2012, 36, 348-378. [CrossRef]

25. Birkmann, J.; Garschagen, M.; Tuan, V.V.; Binh, N.T. Vulnerability, coping and adaptation to water related hazards in the Vietnamese Mekong Delta. In The Mekong Delta System; Springer: Berlin/Heidelberg, Germany, 2012; pp. 245-289.

26. Bennett, K.E.; Tidwell, V.C.; Llewellyn, D.; Behery, S.; Barrett, L.; Stansbury, M.; Middleton, R.S. Threats to a Colorado river provisioning basin under coupled future climate and societal scenarios. Environ. Res. Commun. 2019, 1, 095001. [CrossRef]

27. James, T.; Evans, A.; Madly, E.; Kelly, C. The Economic Importance of the Colorado River to the Basin Region; Final Rep.; L. William Seidman Research Institute: Tempe, AZ, USA, 2014; Volume 54, pp. 1-42.

28. NOAA National Centers for Environmental Information (NCEI). U.S. Billion-Dollar Weather and Climate Disasters. 2021 Available online: https:/ / www.ncdc.noaa.gov/billions/ (accessed on 15 August 2021).

29. Bennett, K.E.; Talsma, C.; Boero, R. Concurrent Changes in Extreme Hydroclimate Events in the Colorado River Basin. Water 2021, 13, 978. [CrossRef]

30. Bennett, K.E.; Bohn, T.J.; Solander, K.; McDowell, N.G.; Xu, C.; Vivoni, E.; Middleton, R.S. Climate-driven disturbances in the San Juan River sub-basin of the Colorado River. Hydrol. Earth Syst. Sci. 2018, 22, 709-725. [CrossRef]

31. Vano, J.A.; Udall, B.; Cayan, D.R.; Overpeck, J.T.; Brekke, L.D.; Das, T.; Hartmann, H.C.; Hidalgo, H.G.; Hoerling, M.; McCabe, G.J.; et al. Understanding Uncertainties in Future Colorado River Streamflow. Bull. Am. Meteorol. Soc. 2014, 95, 59-78. [CrossRef]

32. Kousky, C. Informing climate adaptation: A review of the economic costs of natural disasters. Energy Econ. 2014, 46, 576-592. [CrossRef]

33. Thomalla, F.; Downing, T.; Spanger-Siegfried, E.; Han, G.; Rockström, J. Reducing hazard vulnerability: Towards a common approach between disaster risk reduction and climate adaptation. Disasters 2006, 30, 39-48. [CrossRef] [PubMed] 
34. van Valkengoed, A.M.; Steg, L. Meta-analyses of factors motivating climate change adaptation behaviour. Nat. Clim. Chang. 2019, 9, 158-163. [CrossRef]

35. Wilson, R.S.; Herziger, A.; Hamilton, M.; Brooks, J.S. From incremental to transformative adaptation in individual responses to climate-exacerbated hazards. Nat. Clim. Chang. 2020, 10, 200-208. [CrossRef]

36. Dessai, S.; Hulme, M. Does climate adaptation policy need probabilities? Clim. Policy 2004, 4, 107-128. [CrossRef]

37. Huggel, C.; Scheel, M.; Albrecht, F.; Andres, N.; Calanca, P.; Jurt, C.; Khabarov, N.; Mira-Salama, D.; Rohrer, M.; Salzmann, N.; et al. A framework for the science contribution in climate adaptation: Experiences from science-policy processes in the Andes. Environ. Sci. Policy 2015, 47, 80-94. [CrossRef]

38. US Census Bureau. 2010 TIGER/Line ${ }^{\circledR}$ Shapefiles. Available online: https://www.census.gov/cgi-bin/geo/shapefiles/index. php (accessed on 15 August 2021).

39. Liang, X.; Wood, E.F.; Lettenmaier, D.P. Surface soil moisture parameterization of the VIC-2L model: Evaluation and modification Glob. Planet. Chang. 1996, 13, 195-206. [CrossRef]

40. Livneh, B.; Bohn, T.J.; Pierce, D.W.; Munoz-Arriola, F.; Nijssen, B.; Vose, R.; Cayan, D.R.; Brekke, L. A spatially comprehensive, hydrometeorological data set for Mexico, the U.S., and Southern Canada 1950-2013. Sci. Data 2015, 2, 150042. [CrossRef]

41. Abatzoglou, J.T.; Brown, T.J. A comparison of statistical downscaling methods suited for wildfire applications. Int. J. Climatol. 2012, 32, 772-780. [CrossRef]

42. Yapo, P.O.; Gupta, H.V.; Sorooshian, S. Multi-objective global optimization for hydrologic models. J. Hydrol. 1998, 204, 83-97. [CrossRef]

43. Rana, A.; Moradkhani, H.; Qin, Y. Understanding the joint behavior of temperature and precipitation for climate change impact studies. Theor. Appl. Climatol. 2017, 129, 321-339. [CrossRef]

44. Battiti, R.; Masulli, F. BFGS optimization for faster and automated supervised learning. In Proceedings of the International Neural Network Conference; Springer: Berlin/Heidelberg, Germany, 1990; pp. 757-760.

45. Clark, M.P.; Wilby, R.L.; Gutmann, E.D.; Vano, J.A.; Gangopadhyay, S.; Wood, A.W.; Fowler, H.J.; Prudhomme, C.; Arnold, J.R.; Brekke, L.D. Characterizing uncertainty of the hydrologic impacts of climate change. Curr. Clim. Chang. Rep. 2016, 2, 55-64. [CrossRef]

46. Toya, H.; Skidmore, M. Economic development and the impacts of natural disasters. Econ. Lett. 2007, 94, 20-25. [CrossRef]

47. Boero, R.; Edwards, B.K.; Rivera, M.K. Regional input-output tables and trade flows: An integrated and interregional non-survey approach. Reg. Stud. 2017, 52, 225-238. [CrossRef]

48. Kniesner, T.J.; Viscusi, W.K.; Ziliak, J.P. Policy relevant heterogeneity in the value of statistical life: New evidence from panel data quantile regressions. J. Risk Uncertain. 2010, 40, 15-31. [CrossRef]

49. Kellenberg, D.K.; Mobarak, A.M. Does rising income increase or decrease damage risk from natural disasters? J. Urban Econ. 2008, 63, 788-802. [CrossRef]

50. Milly, P.C.; Dunne, K.A. Colorado River flow dwindles as warming-driven loss of reflective snow energizes evaporation. Science 2020, 367, 1252-1255. [CrossRef]

51. Li, J.; Zhang, Q.; Chen, Y.D.; Singh, V.P. Future joint probability behaviors of precipitation extremes across China: Spatiotemporal patterns and implications for flood and drought hazards. Glob. Planet. Chang. 2015, 124, 107-122. [CrossRef]

52. Yin, J.; Guo, S.; He, S.; Guo, J.; Hong, X.; Liu, Z. A copula-based analysis of projected climate changes to bivariate flood quantiles. J. Hydrol. 2018, 566, 23-42. [CrossRef]

53. Hall, J.W.; Brown, S.; Nicholls, R.J.; Pidgeon, N.F.; Watson, R.T. Proportionate adaptation. Nat. Clim. Chang. 2012, 2, 833-834. [CrossRef]

54. Wobus, C.; Lawson, M.; Jones, R.; Smith, J.; Martinich, J. Estimating monetary damages from flooding in the U nited S tates under a changing climate. J. Flood Risk Manag. 2014, 7, 217-229. [CrossRef]

55. Musselman, K.N.; Lehner, F.; Ikeda, K.; Clark, M.P.; Prein, A.F.; Liu, C.; Barlage, M.; Rasmussen, R. Projected increases and shifts in rain-on-snow flood risk over western North America. Nat. Clim. Chang. 2018, 8, 808-812. [CrossRef]

56. Mahoney, K.; Alexander, M.; Scott, J.D.; Barsugli, J. High-resolution downscaled simulations of warm-season extreme precipitation events in the Colorado Front Range under past and future climates. J. Clim. 2013, 26, 8671-8689. [CrossRef]

57. Albright, E.A.; Crow, D. Beliefs about climate change in the aftermath of extreme flooding. Clim. Chang. 2019, 155, 1-17. [CrossRef]

58. Mulder, K.J. Predicting Responses to Flash Flooding: A Case Study of Boulder, Colorado; East Carolina University: Greenville, NC, USA, 2012

59. Brink, E.; Wamsler, C. Citizen engagement in climate adaptation surveyed: The role of values, worldviews, gender and place. $J$. Clean. Prod. 2019, 209, 1342-1353. [CrossRef]

60. Schwaller, N.L.; Kelmenson, S.; BenDor, T.K.; Spurlock, D. From abstract futures to concrete experiences: How does political ideology interact with threat perception to affect climate adaptation decisions? Environ. Sci. Policy 2020, 112, 440-452. [CrossRef]

61. Fischer, H.W. Decentralization and the governance of climate adaptation: Situating community-based planning within broader trajectories of political transformation. World Dev. 2021, 140, 105335. [CrossRef]

62. Kuklicke, C.; Demeritt, D. Adaptive and risk-based approaches to climate change and the management of uncertainty and institutional risk: The case of future flooding in England. Glob. Environ. Chang. 2016, 37, 56-68. [CrossRef] 
63. Anderegg, W.R.; Prall, J.W.; Harold, J.; Schneider, S.H. Expert credibility in climate change. Proc. Natl. Acad. Sci. USA 2010, 107, 12107-12109. [CrossRef]

64. Lacey, J.; Howden, M.; Cvitanovic, C.; Colvin, R. Understanding and managing trust at the climate science-policy interface. Nat. Clim. Chang. 2018, 8, 22-28. [CrossRef]

65. Fischhoff, B. Nonpersuasive Communication about Matters of Greatest Urgency: Climate Change. Environ. Sci. Technol. 2007, 41, 7204-7208. [CrossRef] [PubMed] 